\title{
Morphine treatment alters nucleotidase activities in rat blood serum
}

This article was published in the following Dove Press journal:

Journal of Experimental Pharmacology

15 December 2012

Number of times this article has been viewed

\author{
Joanna Ripoll Rozisky ${ }^{1,2,4, *}$ \\ Yasmine Nonose ${ }^{1,4, *}$ \\ Gabriela Laste ${ }^{1,2,4}$ \\ Vinicius Souza dos Santos ${ }^{1,4}$ \\ Isabel Cristina de \\ Macedo ${ }^{1,2,4}$ \\ Ana Maria Oliveira \\ Battastini ${ }^{2,3}$ \\ Wolnei Caumo 2,4 \\ Iraci LS Torres ${ }^{1,2,4}$
}

'Laboratório de Farmacologia da Dor e Neuromodulação: Modelos Animais, Departamento de Farmacologia, Instituto de Ciências Básicas da Saúde, ${ }^{2}$ Programa de Pós-Graduação em Medicina, Ciências Médicas, ${ }^{3}$ Departamento de Bioquímica, Instituto de Ciências Básicas da Saúde, Universidade Federal do Rio Grande do Sul, Rio Grande do Sul, Brazil; ${ }^{4}$ Unidade de Experimentação Animal e Grupo de Pesquisa e Pós-Graduação, Hospital de Clínicas de Porto Alegre, Rio Grande do Sul, Brazil

*Both authors contributed equally to this work
Correspondence: Iraci Lucena da Silva Torres

Departamento de Farmacologia, ICBS, UFRGS, Rua Sarmento Leite, 500 sala 202,90050- I 70,

Porto Alegre, RS, Brazil

Tel +555 I 33083183

Fax +55 5। 3308 3।2।

Email iracitorres@gmail.com

\begin{abstract}
Morphine has been widely used in neonatal pain management. However, this treatment may produce adaptive changes in several physiologic systems. Our laboratory has demonstrated that morphine treatment in neonate rats alters nucleoside triphosphate diphosphohydrolase (NTPDase) activity and gene expression in central nervous system structures. Considering the relationship between the opioid and purinergic systems, our aim was to verify whether treatment with morphine from postnatal days 8 (P8) through 14 (P14) at a dose of $5 \mu \mathrm{g}$ per day alters NTPDase and $5^{\prime}$-nucleotidase activities in rat serum over the short, medium, and long terms. After the in vivo assay, the morphine group showed increased hydrolysis of all nucleotides at P30, and a decrease in adenosine 5'-diphosphate hydrolysis at P60. Moreover, we found that nucleotidase activities change with age; adenosine 5'-triphosphate hydrolysis activity was lower at P16, and adenosine 5'-monophosphate hydrolysis activity was higher at P60. These changes are very important because these enzymes are the main regulators of blood nucleotide levels and, consequently, nucleotide signaling. Our findings showed that in vivo morphine treatment alters nucleotide hydrolysis in rat blood serum, suggesting that purine homeostasis can be influenced by opioid treatment during the neonatal period.
\end{abstract}

Keywords: 5'-nucleotidase, morphine, neonate, NTPDase, rat blood serum

\section{Introduction}

Opioids such as morphine are widely used in neonatal pain management because of reported benefits to neonatal behavior and positive outcomes from opioid-based analgesia and anesthesia. ${ }^{1-3}$ However, this practice may produce adaptive changes in the opioid system and associated signaling systems, leading to neuronal plasticity in brain regions and in other tissues and cells expressing opioid receptors, such as in the vascular and cardiac systems. ${ }^{4-6}$

Adenosine $5^{\prime}$-triphosphate (ATP) and its breakdown products, adenosine $5^{\prime}$-diphosphate (ADP), adenosine $5^{\prime}$-monophosphate (AMP), and adenosine, produce marked effects upon a range of biological processes, including neurotransmission and neuromodulation, and play an important role in cardiovascular system regulation..$^{7-9}$ ATP and ADP are released into the bloodstream from vascular smooth muscle, endothelium, and circulating blood cells, and via outflow upon cell lysis. When released, they promote a range of effects on platelets, endothelial tissue, and vascular smooth muscle. ${ }^{10}$ Inactivation of extracellular adenine nucleotides is performed by enzymes from the nucleoside triphosphate diphosphohydrolase family (NTPDases), nucleotide phosphate/phosphodiesterase family, alkaline phosphatases, and 5'-nucleotidase. 
NTPDases hydrolyze ATP and ADP, while 5'-nucleotidase hydrolyzes AMP to adenosine. ${ }^{11}$ These enzymes are ubiquitously coexpressed in endothelial and hematopoietic cells and are the main regulators of purinergic signaling in the blood. ${ }^{12}$ Previous studies have demonstrated the presence of soluble NTPDases in rat blood serum as well as in human blood. ${ }^{13,14}$ Our group has also demonstrated the presence of NTPDase and 5'-nucleotidase in rat blood serum. ${ }^{15-21}$ Furthermore, the presence of NTPDases associated with circulating plasma microparticles has been noted. ${ }^{22}$ These circulating soluble nucleotidases play a role in controlling the availability of ATP, ADP, AMP, and adenosine, keeping extracellular levels within physiological limits and forming an enzymatic pathway with the dual function of removing one signal in the form of ATP and generating another in the form of adenosine. ${ }^{23}$ Thus, soluble NTPDase and $5^{\prime}$-nucleotidase are expressed in mammals and have an important role in maintaining homeostasis.

Our laboratory has investigated the effects of morphine treatment in early life upon E-NTPDase activities in central nervous system structures. We demonstrated that morphine administration in early life alters E-NTPDase activity and gene expression in the rat spinal cord and cerebral cortex. ${ }^{24}$ These relationships between the opioid and purinergic systems have been also studied by other researchers, who have shown that morphine administration promotes adenosine release in the central nervous system. ${ }^{25}$ Similarly, cross-tolerance and cross-withdrawal studies have led to the proposal that a $\mu$-opioid, $\alpha 2$-adrenergic, A1-adenosine receptor complex mediates antinociception in the periphery. ${ }^{26}$ Moreover, morphine has also been shown to stimulate cardiovascular release of adenosine, a well-documented cardioprotective agent, in hypotension. ${ }^{27}$

Considering this close relationship between the opioid and purinergic systems, the present study investigated the activities of NTPDases and 5'-nucleotidase in rat blood serum after repeated morphine exposure in early life. We also investigated the ontogenic profile of these soluble nucleotidases.

\section{Materials and methods Animals}

Eight-day-old male Wistar rats were divided into two groups: saline-control (C) and morphine-treated (M). Naive animals were housed in Plexiglas home cages $(65 \mathrm{~cm} \times 25 \mathrm{~cm} \times 15 \mathrm{~cm})$ with sawdust-covered floors. Animals were kept on a standard 12-hour dark/light cycle (lights on between 0700 and 1900), at room temperature $\left(22^{\circ} \mathrm{C}+2^{\circ} \mathrm{C}\right)$, with free access to food and water. At birth, litters were standardized to contain up to 8 pups per dam, and the pups remained with their mothers until 21 days of age. Rats at postnatal day 8 (P8) were chosen because it is accepted that animals of this age are at a similar stage of neurological development to that of a human newborn. ${ }^{28} \mathrm{It}$ is also accepted that they are in a physiologically immature state $^{29}$ since this period is characterized by major developmental changes in the brain and plasticity of the developing pain system. ${ }^{30-32}$ Animal handling and all experiments were performed in accordance with international guidelines for animal welfare. The protocol of this experimental study was approved by the Ethics Committee of Hospital de Clínicas de Porto Alegre, the institution where the work was conducted. All experiments were performed in accordance with Brazilian Law No 11.794 of October 8, 2008. All efforts were made to minimize animal suffering and use only the number of animals necessary to produce reliable scientific data. The experimental protocol was approved by the Hospital de Clínicas de Porto Alegre Research Ethics Committee.

\section{Reagents}

Nucleotides (ATP, ADP, and AMP), Trizma ${ }^{\circledR}$ base, and Coomassie Brilliant Blue G were purchased from Sigma-Aldrich (St Louis, MO). Morphine sulfate (Dimorf ${ }^{\circledR} 10 \mathrm{mg} / \mathrm{mL}$ ) was provided by Hospital de Clínicas de Porto Alegre, Porto Alegre, RS, Brazil. All other reagents were analytical grade.

\section{Morphine treatment}

Each animal received saline (control group) or morphine (5 $\mu \mathrm{g}$ subcutaneously [sc] in the mid-scapular area; morphine group) starting at postnatal day 8 (P8), then once a day for 7 days, such that at start of treatment (P8) the morphine dose was $0.33 \mathrm{mg} / \mathrm{kg}$, since the animals weighed, on average, about $15 \mathrm{~g}$. At the end of treatment (P14), the dose administered was $0.23 \mathrm{mg} / \mathrm{kg}$, since animals weighed an average of $22 \mathrm{~g}$. This dose was chosen based on the first study conducted by our group in this field because it is the lowest dose capable of inducing analgesia in neonate rats. ${ }^{33}$ Moreover, our group has demonstrated that this dose, when administered for 7 days during the postnatal period, induces changes in NTPDase 1 activity and its mRNA expression pattern in the rat spinal cord and cerebral cortex two days after the end of treatment, which constitutes a short-term effect. ${ }^{24}$ In other studies, we found that this treatment regimen induces hyperalgesic behavior over the medium- and long-term. ${ }^{34}$ All treatments were administered at the same time each day (1100 hours). One milliliter of 
morphine sulfate was diluted in $9 \mathrm{~mL}$ of $0.9 \% \mathrm{NaCl}$ (saline solution). At the end of each stage of the experiment, rats were decapitated for collection of blood samples. Enzyme assays were performed at postnatal day $16(\mathrm{P} 16)(\mathrm{n}=4-5$ per group), postnatal day 30 (P30) ( $\mathrm{n}=5-7$ per group), and postnatal day 60 (P60) $(\mathrm{n}=4-5$ per group).

\section{Isolation of blood serum fraction}

Blood samples were drawn after decapitation, as described previously, and were soon centrifuged in plastic tubes at $5000 \times g$ for 5 minutes at room temperature, without any additives or anticoagulant. ${ }^{14}$ After centrifugation, the supernatant (serum) was separated and kept frozen at $-20^{\circ} \mathrm{C}$ until the assays were performed.

\section{Enzyme assay (determination of NTPDase and 5'-nucleotidase activity)}

ATP and ADP hydrolysis were determined using a modification of the method described by Oses and colleagues. ${ }^{13}$ The reaction mixture, containing $0.5-1.0 \mathrm{mg}$ serum protein in $112.5 \mathrm{mM}$ Tris- $\mathrm{HCl}, \mathrm{pH}$ 8.0, was preincubated for 10 minutes to equilibrate the mixture. The reaction was started by the addition of ATP or ADP (final concentration of $3.0 \mathrm{mM}$ ) and the mixture was incubated at $37^{\circ} \mathrm{C}$, in a final volume of $200 \mu \mathrm{L}$, for 40 minutes. The reaction was stopped by the addition of $200 \mu \mathrm{L} 10 \%$ trichloroacetic acid. All samples were centrifuged at $5000 \times g$ for $5 \mathrm{~min}$ to eliminate precipitated protein and the supernatant was used for colorimetric assay. The inorganic phosphate (Pi) released was measured using the Malachite green method. ${ }^{35}$ AMP hydrolysis was quantified essentially as described above for ATP and ADP hydrolysis. The reaction mixture, containing $3.0 \mathrm{mM}$ AMP as substrate in $100 \mathrm{mM}$ Tris- $\mathrm{HCl}, \mathrm{pH} 7.5$, was incubated with $0.5-1.0 \mathrm{mg}$ serum protein at $37^{\circ} \mathrm{C}$ in a final volume of $200 \mu \mathrm{L}$. All other procedures were the same as described above for ATP and ADP hydrolysis.

For all enzyme assays, incubation times and substrate and protein concentrations were chosen in order to ensure the linearity of the reactions. All samples were run in triplicate. In order to correct for non-enzymatic hydrolysis, we performed controls by adding the serum after the reaction was stopped with trichloroacetic acid. Protein concentration was measured by the Coomassie Blue method, using bovine serum albumin as a standard. ${ }^{36}$ Enzyme activity was expressed as nmol of inorganic phosphate released per minute per milligram of protein $\left(\mathrm{nmol}\right.$ of $\mathrm{Pi} \cdot \mathrm{min}^{-1} \cdot \mathrm{mg}^{-1}$ protein).

\section{Statistical analysis}

Between-group comparisons were performed using the Student's $t$-test for independent samples or one-way analysis of variance (ANOVA) followed by the Student NewmanKeuls (SNK) test, as indicated in the figure legends. The results are expressed as mean \pm standard error of the mean (SEM). Differences were considered significant at $P<0.05$.

\section{Results \\ Effect of morphine treatment on nucleotide hydrolysis in rat blood serum}

We verified the effects of morphine administration in early life on nucleotide hydrolysis in rat serum at different ages. Experiments were performed after daily morphine exposure from postnatal days 8 through 14, and NTPDase and $5^{\prime}$-nucleotidase activities in serum was analyzed at postnatal days 16,30 , and 60 . In this assay, we found no significant between-group differences at P16 (ATP: $\mathrm{C}=1.63 \pm 0.26$; $\mathrm{M}=1.60 \pm 0.37$;DP: $\mathrm{C}=1.2 \pm 0.15 ; \mathrm{M}=1.21 \pm 0.38$; AMP: $\mathrm{C}=1.32 \pm 0.22 ; \mathrm{M}=1.03 \pm 0.1$; Student's $t$-test, $P>0.05$; Figure 1). However, at P30, the morphine group exhibited a significant increase in hydrolysis of all nucleotides when compared to the control group (ATP: $\mathrm{C}=2.14 \pm 0.2$; $\mathrm{M}=4.22 \pm 0.56$; ADP: $\mathrm{C}=2.45 \pm 0.16 ; \mathrm{M}=3.71 \pm 0.47$; AMP: $\mathrm{C}=0.9 \pm 0.22 ; \mathrm{M}=1.85 \pm 0.3$; Student's $t$-test, $P<0.05$; Figure 1). At P60, the morphine group exhibited a significant decrease in ADP hydrolysis compared to

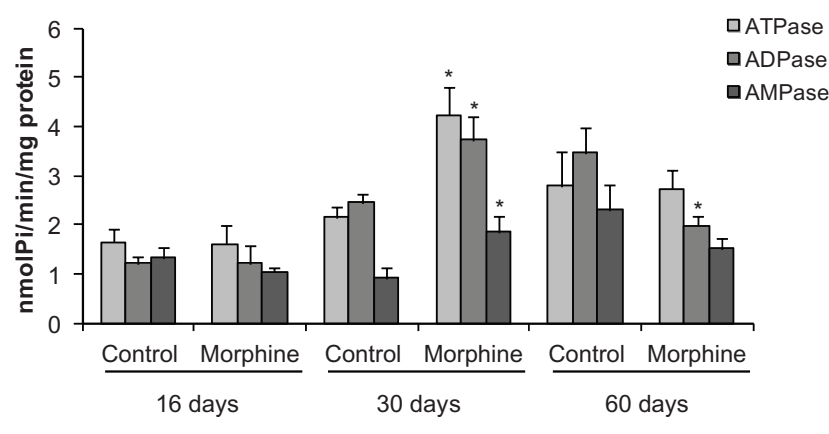

Figure I Effect of morphine administration in early life on NTPDases and $5^{\prime}$-nucleotidase in rat blood serum at PI6, P30, and P60.

Notes: At PI6, no between-group differences in ATP, ADP or AMP hydrolysis were observed (Student's $t$-test, $P>0.05$ ). At P30, however, the morphine group showed an increase in hydrolysis of all nucleotides as compared to the control group (Student's $t$-test, $P<0.05$ ). At P60, ADP hydrolysis was decreased in the morphine group (Student's $t$-test, $P<0.05$ ), while there were no differences in the hydrolysis of other nucleotides (Student's $t$-test, $P>0.05$ for ATP and AMP). Bars represent mean \pm SEM. Specific enzyme activities expressed as $\mathrm{nmol}$ of $\mathrm{Pi} \cdot \mathrm{min}^{-1} \cdot \mathrm{mg}^{-1}$ protein. *Denotes a difference between the control and morphine-treated groups.

Abbreviations: ADP, adenosine 5'-diphosphate; AMP, adenosine 5'-mono-phosphate; ATP, adenosine 5'-triphosphate; NTPDases, nucleoside triphosphate diphosphohydrolase family. 
the control group (ADP $\mathrm{C}=3.45 \pm 0.52 ; \mathrm{M}=1.97 \pm 0.2$; Student's $t$-test, $P<0.05$ ), while there was no difference in the hydrolysis of other nucleotides (ATP: $\mathrm{C}=2.77 \pm 0.71$; $\mathrm{M}=2.72 \pm 0.38$; AMP: $\mathrm{C}=2.29 \pm 0.51 ; \mathrm{M}=1.5 \pm 0.2$; Student's $t$-test, $P>0.05$; Figure 1).

In order to verify the presence of soluble NTPDases in serum after morphine exposure, we analyzed the ratio of ATP/ADP hydrolysis in all ages after morphine treatment. A value of approximately 1:1 was observed, with no significant between-group differences in all ages (P16: $\mathrm{C}=1.06 \pm 0.13 ; \mathrm{M}=1.31 \pm 0.1 ; \mathrm{P} 30: \mathrm{C}=0.93 \pm 0.15$; $\mathrm{M}=1.2 \pm 0.22 ; \mathrm{P} 60: \mathrm{C}=0.96 \pm 0.3 ; \mathrm{M}=1.23 \pm 0.14$; Student's $t$-test, $P>0.05$; Figure 2). These results indicate the presence of NTPDase 1, which hydrolyzes ATP and ADP equally well. ${ }^{37}$

\section{Effect of aging on nucleotide hydrolysis in rat blood serum}

We also assessed whether nucleotide hydrolysis changes with age. We found that ADP hydrolysis was lower at P16 as compared to P30 and P60 $\left(F_{(2,13)}=11.847\right.$; one-way ANOVA, SNK, $P<0.05$; Figure 3A). In contrast, $5^{\prime}$-nucleotidase activity was higher at $\mathrm{P} 60$ than at $\mathrm{P} 16$ or $\mathrm{P} 30\left(F_{(2,13)}=5.044\right.$; one way ANOVA, SNK, $P<0.05$; Figure 3A). No changes in ATP hydrolysis were observed between these ages $\left(F_{(2,13)}=2.010\right.$; one-way ANOVA, $P>0.05$; Figure 3A). The approximate 1:1 ratios of ATP/ADP hydrolysis suggest the presence of NTPDase 1 at all analyzed ages. The ratio between ATPase and ADPase activity remained constant at all analyzed ages $\left(F_{(2,13)}=0.218\right.$; one-way ANOVA, $P>0.05$; Figure 3B).

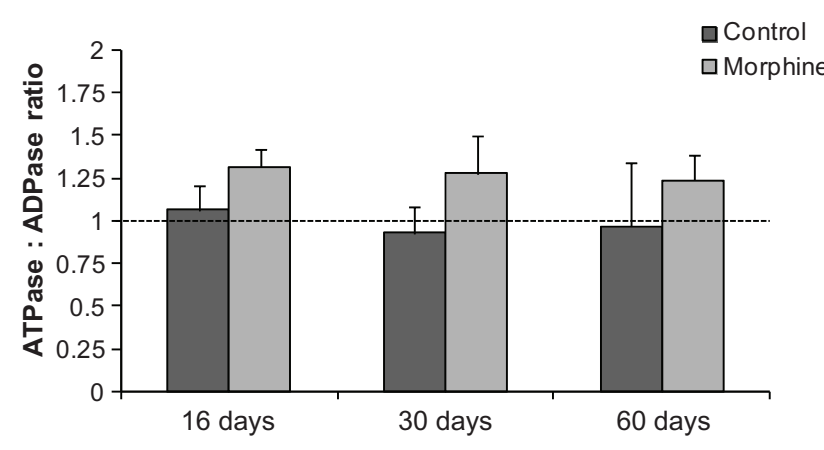

Figure 2 Ratio of ATPase/ADPase activity following morphine administration in early life.

Notes: Bars represent mean \pm SEM. Specific enzyme activities expressed as nmol of $\mathrm{Pi} \cdot \mathrm{min}^{-1} \cdot \mathrm{mg}^{-1}$ protein. There were no between-group differences in the ratio of ATP/ADP hydrolysis at any age (Student's $t$-test, $P>0.05$ ).

Abbreviations: ADP, adenosine 5'-diphosphate; ATP, adenosine $5^{\prime}$-triphosphate.
A
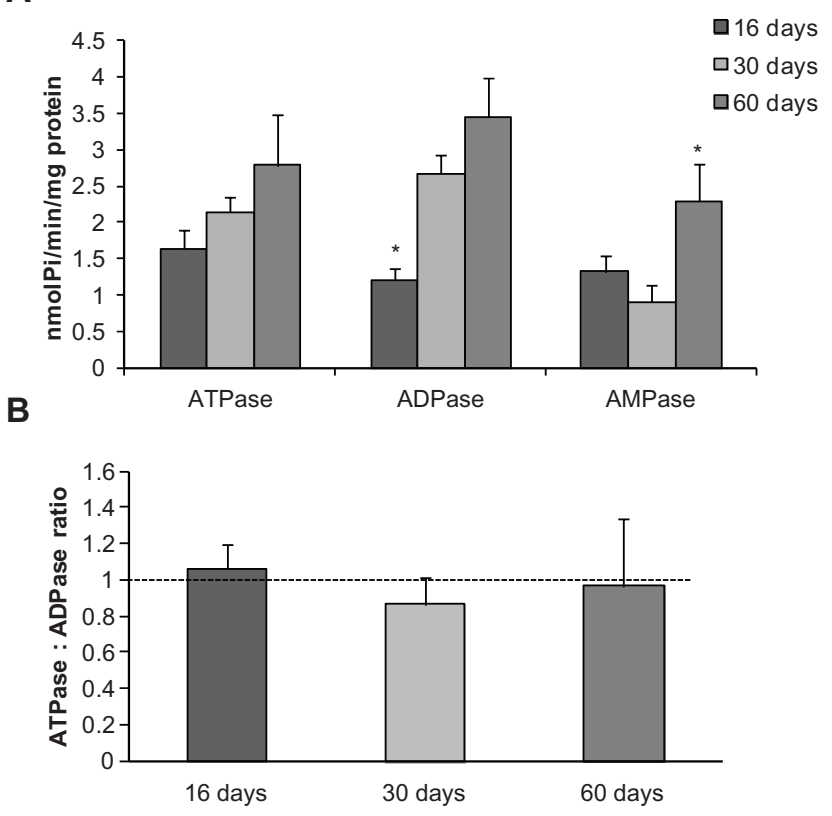

Figure 3 Effect of aging on adenine nucleotide hydrolysis in rat blood serum $(\mathbf{A})$ and on ratio of ATPase/ADPase activity (B).

Notes: At PI6, it was observed a decrease of ADP hydrolysis in comparison to P30 and $\mathrm{P} 60$, while at $\mathrm{P} 60$ it was observed an increase of AMP hydrolysis in comparison to PI 6 and P30 (one way ANOVA, $P>0.05$ for ATP; one way ANOVA, SNK, $P<0.05$ for ADP and AMP). The ratio of ATP/ADP hydrolysis did not change with age (one way ANOVA, $P>0.05$ ). Bars represent mean \pm SEM. Specific enzyme activities expressed as $\mathrm{nmol}$ of $\mathrm{Pi} \cdot \mathrm{min}^{-1} \cdot \mathrm{mg}^{-1}$ protein. *Denotes a difference between ages. Abbreviations: ADP, adenosine 5'-diphosphate; AMP, adenosine 5'-mono-phosphate; ANOVA, analysis of variance; ATP, adenosine $5^{\prime}$-triphosphate; SNK, Student Newman-Keuls.

\section{Discussion}

In this study, we have shown that ATPase, ADPase, and AMPase activities in rat serum are sensitive to morphine administration during the neonatal period. We observed that this treatment positively modulates the hydrolysis of all nucleotides over the medium term (P30). Additionally, over the long term (P60), morphine administration negatively modulates ADP hydrolysis. These results show a long-term effect of morphine treatment in early life upon soluble NTPDases and 5'-nucleotidase in serum. Notably, the parallel increase in ATP/ADP hydrolysis observed at P30 suggests a possible effect on the activity of the soluble NTPDase 1-like enzyme, since parallel behavior for the hydrolysis of these substrates is a characteristic of this enzyme.

Previous studies by our group have demonstrated the presence of soluble NTPDases and 5'-nucleotidase in rat blood serum. ${ }^{15-21}$ Under baseline conditions, vascular endothelial NTPDases and 5'-nucleotidase, acting in concert, regulate nucleotide homeostasis in the vasculature. ${ }^{38,12}$ NTPDase- 1 is expressed on the cell surface of vascular endothelial tissue and smooth muscle cells, and may be released through 
proteolytic cleavage of membrane-bound NTPDase or co-released with ATP and norepinephrine via sympathetic stimulation. ${ }^{38-40}$ Ecto-5' - nucleotidase, which hydrolyzes AMP to adenosine, is attached to the cell surface, and may occur also in a soluble form via cleavage of its glycosylphosphatidylinositol (GPI)-anchor by phospholipase C. ${ }^{41}$ Similarly, it can reduce infarct size and improve cardioprotection both in wild-type and $\mathrm{CD}_{73^{-/}}$mice during acute myocardial ischemia, as well as attenuate tissue damage and improve survival during acute lung injury. ${ }^{42,43}$

NTPDase 1 is notable for its high preference for nucleoside triphosphates and nucleoside diphosphates. ${ }^{44,45}$ When NTPDase 1 is active, extracellular ATP is converted to AMP and then to adenosine by $5^{\prime}$-nucleotidase, and ADP is not an appreciable product. Thus, we can suggest that the difference in ATP and ADP hydrolysis observed at P30 is possibly due to an increase in NTPDase 1-like activity in serum, since our results showed an approximate 1:1 ratio of ATPase/ ADPase. ${ }^{45}$ However, at P60, ADP hydrolysis was decreased. In this way, ATP is converted to ADP by other ATPases, such as NTPDase 2, nucleotide phosphate/phosphodiesterase family members, and alkaline phosphatase, and ADP concentrations will be relatively stable. In this case, AMP (which is the substrate for $5^{\prime}$-nucleotidase) may be reduced, and ADP may accumulate in the bloodstream. However, no change in $5^{\prime}$-nucleotidase activity was observed, making it difficult to infer whether this outcome will result in decreased extracellular adenosine in vivo. Moreover, decreased activity of NTPDase 1 may prolong the effect of ATP and ADP at their respective receptors. ${ }^{46}$ Under our experimental conditions, we did not rule out a potential role of NTPDase 5 and 6 in addition to NTPDase 1 and 2.

In a previous study, we demonstrated that ecto-ATPase, ecto-ADPase, and ecto- $5^{\prime}$-nucleotidase activities in rat spinal cord synaptosomes change in relation to sex and age.$^{47}$ It is likely that these ectonucleotidases, regulating the concentration of ATP and adenosine in the synaptic cleft, play an important role in central nervous system development. ${ }^{48}$ Corroborating these findings, we verified in the present study that the nucleotide hydrolysis profile in the serum of control animals also changes with age, with lower ADPase activity at P16 and higher AMPase activity at P60. This change is very important, because these enzymes are regarded as major regulators of purinergic signaling in blood. ${ }^{49}$

The relationships between the purinergic and vascular systems have been widely studied. ATP can be released into circulation with norepinephrine from sympathetic nerves, causing vasoconstriction via purinergic $\mathrm{P} 2 \mathrm{X}$ receptors on smooth muscle cells. ${ }^{50,51}$ In addition, there is growing evidence for the role of ATP as a neurotransmitter in perivascular non-adrenergic/non-cholinergic nerves, which promote vasodilatation through direct actions on vascular smooth muscle, or indirectly through their effects on the endothelium, mediated by purinergic P2Y receptors. ${ }^{50}$ ADP is a potent platelet aggregator and promotes vasoconstriction. ${ }^{10,52}$ In contrast, adenosine, in addition to its other effects, inhibits platelet aggregation. ${ }^{52}$ Therefore, soluble nucleotidases also may play an important role in maintaining homeostasis and thromboregulation, as they reduce excess levels of these nucleotides in the bloodstream. ${ }^{38}$ This may partially explain why ADPase activity is lower in young life and the AMPase activity is higher in adult life in naïve animals. It is well known that, at P16, the rat cardiovascular system is still immature, and that modulation of nucleotide levels is very important for development of cardiac and vascular functions and contributes to the regulation of vascular tone. ${ }^{53}$ In addition, the regulation of ATP-metabolizing enzymes in blood likely plays a significant role in the normal function of this tissue at different ages. Conversely, 5'-nucleotidase activity is higher in adult life. This can lead to increased blood levels of adenosine, which can thus exert its vascular and cardioprotective effects. ${ }^{27}$

Studies regarding the relationship between opioid and cardiovascular systems are well-known; chronic opioid- $\mu$ receptor stimulation can decrease muscle sympathetic nerve activity and plasma levels of norepinephrine. ${ }^{54}$ Furthermore, low doses of morphine have been found to elicit cardioprotective effects against myocardial ischemia-reperfusion through modulation of sympathetic nervous system activity, thus suggesting an additional role of the central nervous system in the cardioprotective effect of opioid drugs. ${ }^{55}$ In a previous study, we demonstrated that norepinephrine increases soluble NTPDase 1-like activity in blood serum through a direct stimulatory effect. ${ }^{20}$ This positive modulatory effect suggests a new role for circulating norepinephrine in regulation of nucleotidases (likely soluble NTPDase-1) pathway, where it may induce a decrease in extracellular ATP and ADP in the circulation. ${ }^{20}$ Taking into account that morphine treatment in early life changes soluble nucleotidase activities in rat serum over the medium- and long-term, observed increased NTPDase 1-like and 5'-nucleotidase at P30, and decreased NTPDase 1-like at P60, we can suggest that, at these different ages, soluble nucleotidases modulate the cardiovascular tonus by controlling nucleotide levels in the blood serum, such as increased adenosine levels at P30 and increased ADP levels at P60. Although adenosine is well-known to inhibit 
platelet aggregation and ADP induces platelet aggregation and vasoconstriction, we do not know whether nucleotides exert the mentioned functions in the medium- and longterm after morphine treatment in early life, as several other factors, are very important in determining the direction of the vascular response elicited by adenine nucleotides, such as the presence and nature of the purinoceptor subtype involved and its location in relation to the structural components of the vascular wall. Other studies concerning the functional relevance of these changes are warranted.

In light of the above, we suggest that the results of the changes on nucleotidase activities lasted for the medium and long term after morphine treatment, ie, after 2 and 6 weeks posttreatment. These results suggest that there is no circulating morphine in the blood serum and thus morphine was not able to act directly on nucleotidase structures. Thereby, morphine treatment during the neonatal period could act at transcriptional level in a manner similar to that showed by our previous work when we observed these changes in central nervous system structures. ${ }^{24}$ In addition, we emphasize that the peak of enzyme protein expression does not always coincide with enzyme activity. ${ }^{56,57}$ For example, high protein levels of NTPDase 1 from synaptic plasma membrane from the cerebral cortex did not match the peak of enzymatic activity. ${ }^{57}$ These findings indicate that changes in enzyme activity are not necessarily reflected by similar changes in expression levels.

In summary, our findings show that morphine treatment during the neonatal period alters nucleotide hydrolysis in rat serum, suggesting that purine homeostasis can be influenced by opioid treatment during the neonatal period. This modulator effect of morphine may involve the maintenance of extracellular nucleotide levels over the medium- and long-term and, consequently, contribute to the inhibition of platelet aggregation and thrombus formation induced by ATP and ADP. Moreover, we propose that this change in the nucleotide pathway may be considered a new guide for the understanding of some side effects after discontinuation of morphine treatment.

\section{Acknowledgments}

This study was supported by the Brazilian National Council for Scientific and Technological Development - CNPq (ILS Torres); the National Coordination for the Development of Higher Education Personnel, CAPES (JR Rozisky, G Laste, IC de Macedo); Fundação de Amparo à Pesquisa do Rio Grande do Sul, FAPERGS (V S dos Santos; PRONEM 03/2011); the Graduate Research Group (GPPG) of Hospital de Clínicas de Porto Alegre (ILS Torres, Grant 08345); and the Office of the Vice-Provost for Research, Universidade
Federal do Rio Grande do Sul, PROPESQ-UFRGS (Y Nonose).

\section{Disclosure}

The authors report no conflicts of interest in this work. The authors alone are responsible for the content and writing of the paper.

\section{References}

1. Arnold JH, Truog RD, Orav EJ, Scavone JM, Hershenson MB. Tolerance and dependence in neonates sedated with fentanyl during extracorporeal membrane oxygenation. Anesthesiology. 1990;73(6):1136-1140.

2. Franck L, Vilardi J. Assessment and management of opioid withdrawal in ill neonates. Neonatal Netw. 1995;14(2):39-48.

3. Franck LS, Vilardi J, Durand D, Powers R. Opioid withdrawal in neonates after continuous infusions of morphine or fentanyl during extracorporeal membrane oxygenation. Am J Crit Care. 1998;7(5):364-369.

4. Nestler EJ, Aghajanian GK. Molecular and cellular basis of addiction. Science. 1997;278(5335):58-63.

5. Ueda H. Locus-specific involvements of anti-opioid systems in morphine tolerance and dependence. Ann NY Acad Sci. 2004;1025:376-382.

6. Pugsley MK. The diverse molecular mechanism responsible for the actions of opioids on the cardiovascular system. Pharmacol Ther. 2002;93(1):51-57.

7. Burnstock G. Physiology and pathophysiology of purinergic neurotransmission. Physiol Rev. 2007;87(2):659-797.

8. Burnstock G. Purinergic signalling and disorders of the central nervous system. Nat Rev Drug Discov. 2008;7(7):575-590.

9. Erlinge D, Burnstock G. P2 receptors in cardiovascular regulation and disease. Purinergic Signal. 2008;4(1):1-20.

10. Kunapuli SP, Daniel JL. P2 receptor subtypes in the cardiovascular system. Biochem J. 1998;336(Pt 3):513-523.

11. Zimmermann H. Extracellular metabolism of ATP and other nucleotides. Naunyn Schmiedebergs Arch Pharmacol. 2000;362(4-5):299-309.

12. Robson SC, Wu Y, Sun X, Knosalla C, Dwyer K, Enjyoji K. Ectonucleotidases of CD39 family modulate vascular inflammation and thrombosis in transplantation. Semin Thromb Hemost. 2005;31(2):217-233.

13. Oses JP, Cardoso CM, Germano RA, et al. Soluble NTPDase: an additional system of nucleotide hydrolysis in rat blood serum. Life Sci. 2004;74(26):3275-3284.

14. Yegutkin GG. Kinetic analysis of enzymatic hydrolysis of ATP in human and rat blood serum. Biochemistry (Mosc). 1997;62(6):619-622.

15. Torres IL, Buffon A, Dantas G, et al. Chronic stress effects on adenine nucleotide hydrolysis in the blood serum and brain structures of rats. Pharmacol Biochem Behav. 2002;74(1):181-186.

16. Torres IL, Fürstenau CR, Rossi G, et al. Methylprednisolone administration alters adenine nucleotide hydrolysis in rat blood serum. Eur J Pharmacol. 2007;560(2-3):212-215.

17. Böhmer AE, Fürstenau CR, Torres IL, et al. The effect of stress upon hydrolysis adenine nucleotides in blood serum of rats. Pharmacol Biochem Behav. 2003;75(2):467-471.

18. Siqueira IR, Elsner VR, Rilho LS, et al. A neuroprotective exercise protocol reduces the adenine nucleotide hydrolysis in hippocampal synaptosomes and serum of rats. Brain Res. 2010;1316:173-180.

19. Detanico BC, de Souza A, Medeiros LF, et al. 24-hour temporal pattern of NTPDase and 5'-nucleotidase enzymes in rat blood serum. Chronobiol Int. 2004;27(9-10):1751-1561.

20. Detanico BC, Rozisky JR, Battastini AM, Torres IL. Physiological level of norepinephrine increases adenine nucleotides hydrolysis in rat blood serum. Purinergic Signal. 2011;7(4):373-379.

21. Souza A, Detanico BC, Medeiros LF, et al. Effects of restraint stress on the daily rhythm of hydrolysis of adenine nucleotides in rat serum. J Circadian Rhythms. 2011;28:9-7. 
22. Banz Y, Beldi G, Wu Y, Atkinson B, Usheva A, Robson SC. CD39 is properties and impacts endothelial activation. $\mathrm{Br} J$ Haematol. 2008;142(4):627-637.

23. Agteresch HJ, Dagnelie PC, van den Berg JW, Wilson JH. Adenosine triphosphate: established and potential clinical applications. Drugs. 1999;58(2):211-232.

24. Rozisky JR, da Silva RS, Adachi LS, et al. Neonatal morphine exposure alters E-NTPDase activity and gene expression pattern in spinal cord and cerebral cortex of rats. Eur J Pharmacol. 2010;642(1-3):72-76.

25. Sawynok J, Liu XJ. Adenosine in the spinal cord and periphery: release and regulation of pain. Prog Neurobiol. 2003;69(5):313-340.

26. Aley KO, Levine JD. Multiple receptors involved in peripheral alpha 2, $\mathrm{mu}$, and A1 antinociception, tolerance, and withdrawal. J Neurosci. 1997;17(2):735-744.

27. Calignano A, Persico P, Mancuso F, Sorrentino L. Adenosine release in morphine-induced hypotension in rats. Gen Pharmacol. 1992;23(1):7-10.

28. Fitzgerald M, Anand KJ. Developmental neuroanatomy and neurophysiology of pain. In: Schechter NL, Berde CB, Yaster M, editors. Pain in Infant, Children, and Adolescents. Baltimore: Williams \& Wilkins; 1993:11-31.

29. Pattinson D, Fitzgerald M. The neurobiology of infant pain: development of excitatory and inhibitory neurotransmission in the spinal dorsal horn. Reg Anesth Pain Med. 2004;29(1):36-44.

30. Bishop B. Neural plasticity: Part 2. Postnatal maturation and functioninduced plasticity. Phys Ther. 1982;62(8):1132-1143.

31. Kim JJ, Foy MR, Thompson RF. Behavioral stress modifies hippocampal plasticity through N-methyl-D-aspartate receptor activation. Proc Natl Acad Sci U S A. 1996;93(10):4750-4753.

32. Rabinowicz T, de Courten-Myers GM, Petetot JM, Xi G, de los Reyes E. Human cortex development: estimates of neuronal numbers indicate major loss late during gestation. J Neuropathol Exp Neurol. 1996;55(3):320-328

33. Rozisky JR, Dantas G, Adachi LS, et al. Long-term effect of morphine administration in young rats on the analgesic opioid response in adult life. Int J Dev Neurosci. 2008;26(6);561-565.

34. Rozisky JR, Medeiros LF, Adachi LS, et al. Morphine exposure in early life increases nociceptive behavior in a rat formalin tonic pain model in adult life. Brain Res. 2011;1367:122-129.

35. Chan KM, Delfert D, Junger KD. A direct colorimetric assay for $\mathrm{Ca}^{2+}$ stimulated ATPase activity. Anal Biochem. 1986;157(2):375-380.

36. Bradford MM. A rapid and sensitive method for the quantitation of microgram quantities of protein utilizing the principle of protein-dye binding. Anal Biochem. 1976;72:248-254.

37. Kukulski F, Lévesque SA, Lavoie EG, et al. Comparative hydrolysis of P2 receptor agonists by NTPDases 1, 2, 3 and 8. Purinergic Signal. 2008;1(12):193-204.

38. Marcus AJ, Broekman MJ, Drosopoulos JH, et al. Metabolic control of excessive extracellular nucleotide accumulation by CD39/ecto-nucleotidase-1: implications for ischemic vascular diseases. J Pharmacol Exp Ther. 2003;305(1):9-16.

39. Mihaylova-Todorova ST, Todorov LD, Westfall DP. Enzyme kinetics and pharmacological characterization of nucleotidases released from the guinea pig isolated vas deferens during nerve stimulation: evidence ATPase and a soluble ecto-5'-nucleotidase-like AMPase. J Pharmacol Exp Ther. 2002;302(3):992-1001. incorporated into plasma microparticles where it maintains functional for a soluble ecto-nucleoside triphosphate diphosphohydrolase-like

40. Todorov LD, Mihaylova-Todorova S, Westfall TD, et al. Neuronal release of soluble nucleotidases and their role in neurotransmitter inactivation. Nature 1997;387(6628):76-79.

41. Robson SC, Sévigny J, Zimmermann H. The ENTPDase family of ectonucleotidases: Structure function relationships and pathophysiological significance. Purinergic Signal. 2006;2(2):409-430.

42. Eckle T, Krahn T, Grenz A, et al. Cardioprotection by ecto-5' nucleotidase (CD73) and A2B adenosine receptors. Circulation. 2007a;115(12):1581-1590.

43. Eckle T, Fullbier L, Wehrmann M, et al. Identification of ectonucleotidases CD39 and CD73 in innate protection during acute lung injury. J Immunol. 2007b;178(12):8127-8137.

44. Zimmermann H. Ecto-nucleotidases. In: Abbrachio MP, Williams M, editors. Handbook of Experimental Pharmacology. Purinergic and Pyrimidergic Signalling. New York: Springer; 2001:209-250.

45. Zimmermann H. Ectonucleotidases in the nervous system. Novartis Found Symp. 2006;276:113-128, discussion 128-130, 233-237, 275-281.

46. Gendron FP, Benrezzak O, Krugh BW, Kong Q, Weisman GA, Beaudoin AR. Purine signaling and potential new therapeutic approach: possible outcomes of NTPDase inhibition. Curr Drug Targets 2002;3(3):229-245

47. Torres IL, Battastini AM, Buffon A, et al. Ecto-nucleotidase activities in spinal cord of rats changes as function of age. Int $J$ Dev Neurosci. 2003;21(8):425-429.

48. Ralevic V. Purines as neurotransmitters and neuromodulators in blood vessels. Curr Vasc Pharmacol. 2009;7(1):3-14.

49. Yegutkin GG. Nucleotide- and nucleoside-converting ectoenzymes: important modulators of purinergic signaling cascade. Biochim Biophys Acta. 2008;1783(5):673-694.

50. Westfall DP, Todorov LD, Mihaylova-Todorova ST. ATP as a cotransmitter in sympathetic nerves and its inactivation by releasable enzymes. J Pharmacol Exp Ther. 2002;303(2):439-444.

51. Furukoji E, Tanaka N, Yamashita A, et al. Ecto-nucleoside triphosphate diphosphohydrolase inhibits ATP- and ADP-induced vasoconstriction. Thromb Res. 2008;121(4);583-585.

52. Zimmermann H, Braun N. Ecto-nucleotidases-molecular structures, catalytic properties, and functional roles in the nervous system. Prog Brain Res. 1999;120:371-385

53. Kojima M, Sperelakis N, Sada H. Ontogenesis of transmembrane signaling systems for control of cardiac Ca2+ channels. J Dev Physiol. 1990;14(4):181-219.

54. Kienbaum P, Heuter T, Michel MC, Scherbaum N, Gastpar M, Peters J. Chronic $\mu$-opioid receptor stimulation in humans decreases muscle sympathetic nerve activity. Circulation. 2001;103(6):850-855.

55. Groban L, Vernon JC, Butterworth J. Intrathecal morphine reduces infarct size in a rat model of ischemia-reperfusion injury. Anesth Analg 2004;98(4):903-909.

56. Banjac A, Nedeljković N, Horvat A, Kanazir D, Nikezić G. Ontogenic profile of ecto-ATPase activity in rat hippocampal and caudate nucleus synaptic plasma membrane fractions. Physiol Res. 2001;50(4): 411-418.

57. Nedeljkovic N, Banjac A, Horvat A, Stojiljkovic M, Nikezic G. Developmental profile of NTPDase activity in synaptic plasma membranes isolated from rat cerebral cortex. Int J Dev Neurosci. 2005 23(1):45-51.

\section{Dovepress}

\section{Publish your work in this journal}

The Journal of Experimental Pharmacology is an international, peerreviewed, open access journal publishing original research, reports, reviews and commentaries on all areas of laboratory and experimental pharmacology. The manuscript management system is completely online and includes a very quick and fair peer-review system.
Visit http://www.dovepress.com/testimonials.php to read real quotes from published authors. 